\title{
Prognosis of stroke in the south of Greece: 1 year mortality, functional outcome and its determinants: the Arcadia Stroke Registry
}

\author{
K N Vemmos, M L Bots, P K Tsibouris, V P Zis, C E Takis, D E Grobbee,
} S Stamatelopoulos

\begin{abstract}
Objectives-For Greece, data on incidence of stroke, type of stroke, and prognosis of stroke is limited. Recently, results on incidence of stroke were published. Here 1 year mortality, functional outcome after a first ever stroke, and determinants of the prognosis are described.

Methods-A population based registry was established in the Arcadia area, located in eastern central Peloponessos in southern Greece. Between 1 November 1993 and 31 October 1995, 555 patients with a first ever stroke were identified using information from death certificates, hospital records, public health centres and general practitioners. Extensive information on cardiovascular risk factors and stroke characteristics was obtained. After 1 year a modified Rankin score was determined in all surviving patients.

Results-After 1 year of follow up, 204 $(36.8 \%)$ patients died. The probability of survival 1 year after stroke was higher for cerebral infarction than for intracerebral haemorrhage; $67.8 \%$ (95\% confidence interval (95\% CI) 64-72) and 46.4\% (35-57), respectively. Of the survivors, $68.9 \%$ had either no symptoms or symptoms that would not interfere with their capacity to look after themselves (Rankin score 0 to 2). Increasing age and low Glasgow coma scale score were the most powerful predictors of death within 1 year $(p<0.01)$, whereas increasing age, atrial fibrillation, and low Glasgow coma scale score were the most important predictors of functional outcome 1 year after a stroke $(\mathbf{p}<0.01)$.

Conclusions-One year mortality from stroke in Greece is similar to that of other industrialised countries. The most important factors that affect the prognosis of a patient with a first ever stroke are increasing age, stroke severity, and atrial fibrillation.

(F Neurol Neurosurg Psychiatry 2000;69:595-600)
\end{abstract}

Keywords: risk factors; prognosis; stroke outcome; Greece

Correspondence to : $\mathrm{Dr}$ Kostas N Vemmos

vemmosk@ath.forthnet.gr

Received 20 April 1999 and in final form

11 July 2000

Accepted 11 July 2000
States and in most western and northern European countries. ${ }^{23}$ By contrast, in eastern Europe stroke mortality has remained stable or even increased over this period. ${ }^{2}$ These secular trends suggest substantial potential for prevention of stroke through beneficial changes in risk factors and case fatality. Similarly, recent developments in treatment of acute stroke and in care after the acute phase have provided important evidence to further prevent recurrent cardiovascular and cerebrovascular disease in patients with a non-fatal stroke. ${ }^{4}$

Studies on geographical patterns of stroke mortality show large differences across countries and across geographical areas within countries. $^{5-7}$ These geographical differences seem to persist over the years. Within Europe, a twofold to threefold difference in stroke mortality is found. ${ }^{8}$ The reasons for these considerable differences are not yet fully understood. The wide variation in stroke mortality may be attributed to differences in incidence of stroke and to differences in case fatality of stroke. Furthermore, the relative contribution of several risk factors to the prognosis of stroke may differ across countries, which implies the need for country specific targeted approaches to prevent stroke recurrence.

We previously reported stroke incidence and short term case fatality from the first prospective stroke registry in a defined population from southern Greece with a typical Mediterranean lifestyle. ${ }^{9}$ In this report we present the 1 year stroke prognosis and its determinants.

\section{Patients and methods}

A population based registry was established in the Arcadia area, one of 51 prefectures located in east-central Peloponessos, in the southern part of Greece (fig 1). The permanent resident population in 1991 aged 20 years and over comprised 41864 men and 38910 women, for a total of 80774 inhabitants. Details of the Arcadia Stroke Registry in methodology have been reported previously. ${ }^{9}$ In summary, patients were enrolled in the study in one of the following ways: (a) medical records for patients in hospital; (b) notifications from general practitioners (GPs) and private family physicians; (c) medical records from health centres; and (d) death certificates. If someone experienced a possible stroke, the patient would promptly be examined by the local GP and transported by ambulance to the nearest health centre or to the local hospital. Patients admitted to hospital were examined soon after admission and were 


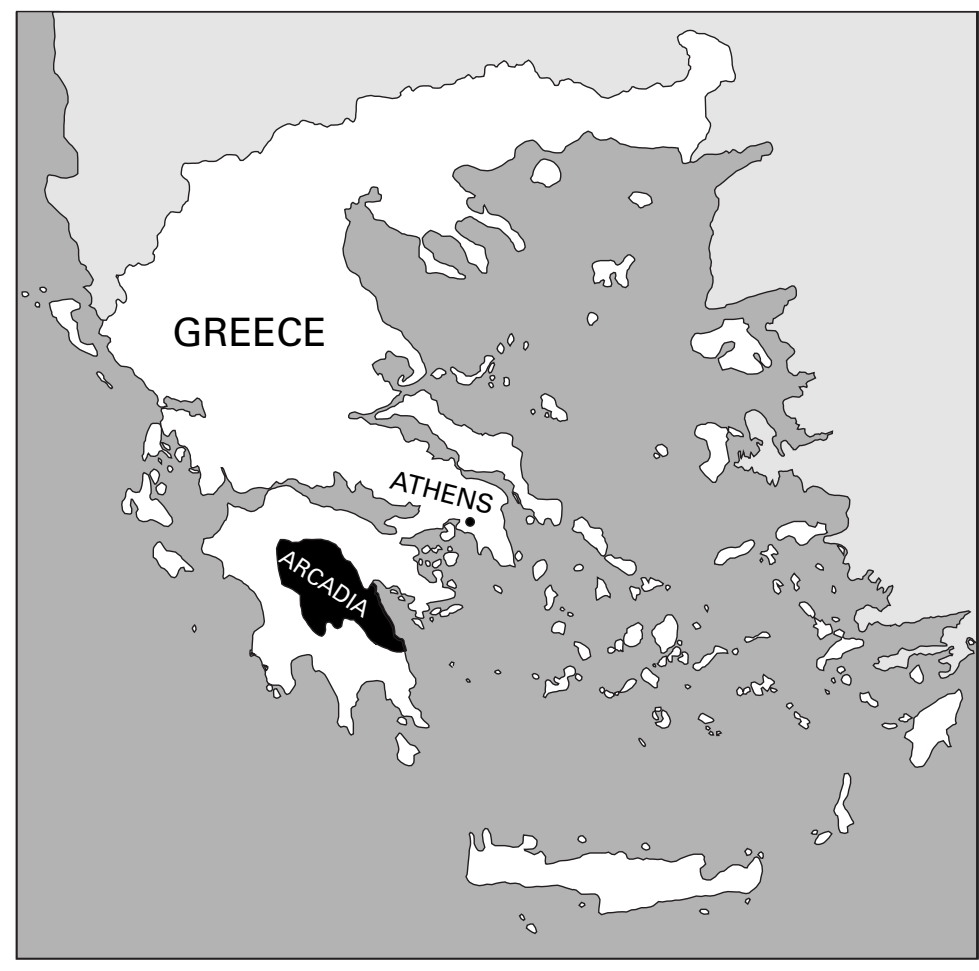

Figure 1 Geographical location of the study area.

monitored often until discharge. On a monthly basis, we visited the health centres to obtain information from the medical records. General practitioners and private family practitioners were also contacted. All the data were collected prospectively. Medical history was obtained and presence of risk factors was evaluated by one of the us (PKT) on the day of admission. For patients not in hospital we used information from notifications of the health centres and attending physicians. Brain CT was made as soon as possible but mostly during the first week after stroke onset. A total of 555 patients with first ever stroke that occurred from 1 November 1993 to 31 October 1995 among residents in the study area was registered. Subjects aged 18 years or below, those with a recurrent stroke, and those with a transient ischaemic attack were not included in the registry. All patients were followed up until death or up to 1 year after their stroke. Outcome data were available for 554 patients at 1 month and for 532 patients at 1 year.

\section{STUDY DEFINITION}

We used the World Health Organisation (WHO) definition of stroke as a rapid onset of clinical signs of a local or global disturbance of cerebral function, lasting more than 24 hours or leading to death, with no apparent nonvascular cause. ${ }^{10}$ Strokes were classified into subtypes by aetiopathogenetic mechanisms using international criteria, as have been described in detail elsewhere. ${ }^{9}$ Patients without CT were classified based on the most likely clinical choice in which the Guy's Hospital stroke diagnostic score (GHSDS) was used ${ }^{11}$; possible intracerebral haemorrhage GHSDS $>25$ (90\% probability). ${ }^{12}$
Risk factors

A history of hypertension was defined as systolic blood pressure $>160 \mathrm{~mm} \mathrm{Hg}$, or diastolic blood pressure $>90 \mathrm{~mm} \mathrm{Hg}$, or both diagnosed at least twice before the stroke or documented treatment of hypertension. Smoking was considered present when a patient smoked daily previous to the stroke and was considered absent when the patient had never smoked or stopped smoking for at least 1 year preceding the stroke event. Diabetes mellitus was defined as use of a blood sugar lowering drug before the occurrence of the stroke or a documented fasting blood glucose concentration exceeding $120 \mathrm{mg} / \mathrm{dl}$. Hypercholesterolaemia was considered if one plasma cholesterol value was $240 \mathrm{mg} / \mathrm{dl}$ before stroke or at the time of admission. Severe alcohol consumption was defined as $60 \mathrm{~g}$ /day for men and $40 \mathrm{~g} /$ day for women. A history of a transient ischaemic attack was defined when a patient had an attack diagnosed by a neurologist as a temporary, focal neurological deficit presumably related to ischaemia and lasting less than 24 hours. History of coronary heart disease (myocardial infarction, angina pectoris, congestive heart failure) was assessed by questionnaire without medical confirmation if it was diagnosed by a cardiologist and the patient had been given a relevant treatment. Atrial fibrillation was diagnosed by ECG for patients in hospital; for those not in hospital at least one ECG with documentation of atrial fibrillation in the year before the event was required.

For each stroke case, a Glasgow coma score was obtained in surviving patients in hospital by one of the authors (PKT) on the day of admission. For those not in hospital we used information from notifications of the health centres and attending physicians. For each patient with stroke, a modified Rankin scale was applied at discharge from the hospital and at the final follow up 1 year after stroke onset. ${ }^{13}$ Patients were classified into six categories: (0) no symptoms at all; (1) no significant disability, despite symptoms able to carry out all usual duties and activities; (2) slight disability, unable to carry out all previous activities but able to look after their own affairs without assistance; (3) moderate disability, requiring some help but able to walk without assistance; (4) moderate to severe disability, unable to walk without assistance, unable to attend to their own body without assistance; (5) severe disability, bedridden, incontinent, requiring constant nursing care and attention. Handicap for patients not in hospital was obtained by questionnaire from attending physicians or by examination of the patient at home by one of us.

\section{DATA ANALYSIS}

Short term case fatality was defined as death before 28 days after the stroke onset. Long term case fatality was defined as death within 1 year. Results are presented by age and sex, and by type of stroke. The modified Rankin scale was dichotomised according to independence for looking after their own affairs $(0,1,2)$ or dependence for looking after their own affairs 
$(3,4,5) \cdot{ }^{12}$ Proportions are presented by age and sex, and by type of stroke.

Continuous data were analyzed using unpaired $t$ tests and categorical data using Fisher's exact test. The Kaplan-Meier method was used to estimate the probability of survival after 1 year from stroke onset. Comparisons between subgroups were evaluated by the log rank test. To evaluate which factors contribute to 1 year death, a univariable Cox's proportional hazards model was used. Those factors that contributed to the outcome in the univariable analyses at $\mathrm{p}$ values $<0.10$ were included in the multivariable model. A similar regression model was used in which all patients that had died within 28 days were excluded to explore potential different contributions of risk factors to short term and long term follow up. Associations are presented as hazard ratios with their corresponding 95\% contidence interval $(95 \% \mathrm{CI})$.

For functional outcome a logistic regression model was taken in which dependence (yes-no) was used as the outcome variable. When the number of events allowed, analyses were performed for cerebral infarction and intracerebral haemorrhage separately. As the analyses for men were similar to those for women, only results from sex adjusted analyses are presented.

\section{Results}

From 1 November 1993 to 31 October 1995, a total of 555 first ever strokes was registered during a follow up of 165548 person-years. Over $90 \%$ of the patients were admitted to hospital ( $n=513), 6.5 \%$ came from health centres $(n=36)$ and $1.1 \%$ came from death certificates $(n=6)$. In table 1 general characteristics and stroke risk factors of the study population are presented. There were $309(55.6 \%)$ men and $246(44.4 \%)$ women. The mean age for men was 75 (SD 11.9) years and 76 (SD 11.2) years for women. Smoking and frequency of severe alcohol consumption differed significantly between men and women (table 1). Atrial fibrillation was very common among patients with stroke, and occurred in $30.8 \%$ of men and in $38.3 \%$ of women.

Brain CT was present for $454(81.8 \%)$ of the patients, with a median delay of 7 days from stroke onset. Five patients had the CT during the $3 \mathrm{rd}$ week. In the remainder of the patients, type of stroke was assessed using the GHSDS In $17(3.1 \%)$ patients, a distinction of stroke

Table 1 General characteristics (mean (SD)) of the study population (\%)

\begin{tabular}{lrrrrr}
\hline Risk factor & Men $(n=309)$ & Women $(n=246)$ & p Value \\
\hline Age (y) & $75.1(11.9)$ & $76.1(11.3)$ & 0.32 \\
Current smoker & 105 & $(34.0)$ & 5 & $(2.1)$ & $<0.01$ \\
Hypertension & 242 & $(78.4)$ & 208 & $(84.6)$ & 0.06 \\
Hypercholesterolaemia & 127 & $(41.1)$ & 114 & $(46.4)$ & 0.22 \\
Alcohol consumption & 64 & $(20.8)$ & 4 & $(1.7)$ & $<0.01$ \\
Diabetes mellitus & 86 & $(27.9)$ & 79 & $(32.2)$ & 0.30 \\
Transient ischaemic attacks & 59 & $(19.1)$ & 33 & $(13.5)$ & 0.08 \\
Atrial fibrillation & 95 & $(30.8)$ & 94 & $(38.3)$ & 0.07 \\
Myocardial infarction & $32(10.4)$ & 17 & $(7.0)$ & 0.17 \\
Angina pectoris & $36(11.7)$ & 38 & $(15.5)$ & 0.20 \\
Congestive heart failure & 49 & $(15.9)$ & 34 & $(13.9)$ & 0.55 \\
Valvular heart disease & 7 & $(2.3)$ & 8 & $(3.3)$ & 0.60 \\
\hline
\end{tabular}

$\mathrm{p}$ Values for the difference between men and women.
Table 2 One year crude mortality from stroke (\%) by type of stroke and sex

\begin{tabular}{|c|c|c|c|c|c|c|}
\hline \multirow[b]{2}{*}{ Age (y) } & \multicolumn{2}{|c|}{ All events } & \multicolumn{2}{|c|}{$\begin{array}{l}\text { Cerebral } \\
\text { infarction }\end{array}$} & \multicolumn{2}{|c|}{$\begin{array}{l}\text { Intracerebral } \\
\text { haemorrhage }\end{array}$} \\
\hline & $D / S$ & $\%$ & $D / S$ & $\%$ & $D / S$ & $\%$ \\
\hline \multicolumn{7}{|l|}{ Men: } \\
\hline $18-54$ & $3 / 18$ & 16.7 & $2 / 14$ & 14.3 & $1 / 3$ & 33.3 \\
\hline $55-64$ & $7 / 36$ & 19.4 & $3 / 28$ & 10.7 & $3 / 6$ & 50.0 \\
\hline $65-74$ & $18 / 74$ & 24.3 & $11 / 56$ & 19.6 & $6 / 17$ & 35.3 \\
\hline $75-84$ & $40 / 106$ & 37.7 & $27 / 89$ & 30.3 & $10 / 14$ & 71.4 \\
\hline$\geqslant 85$ & $38 / 75$ & 50.7 & $32 / 63$ & 50.8 & $5 / 10$ & 50.0 \\
\hline Total & $\begin{array}{l}106 / \\
309\end{array}$ & 34.3 & $75 / 250$ & 30.0 & $25 / 50$ & 50.0 \\
\hline \multicolumn{7}{|l|}{ Women: } \\
\hline $18-54$ & $2 / 9$ & 22.2 & $0 / 4$ & 0 & $2 / 4$ & 50.0 \\
\hline $55-64$ & $7 / 29$ & 24.1 & $3 / 19$ & 15.8 & $3 / 8$ & 37.5 \\
\hline $65-74$ & $18 / 55$ & 32.7 & $9 / 41$ & 30.0 & $2 / 5$ & 40.0 \\
\hline $75-84$ & $40 / 99$ & 40.4 & $32 / 90$ & 35.6 & $4 / 5$ & 80.0 \\
\hline$\geqslant 85$ & $31 / 53$ & 58.5 & $22 / 43$ & 51.2 & $5 / 5$ & 100.0 \\
\hline Total & $98 / 245$ & 40.0 & $66 / 197$ & 33.5 & $16 / 27$ & 59.3 \\
\hline \multicolumn{7}{|c|}{ All subjects: } \\
\hline $18-54$ & $5 / 27$ & 18.5 & $2 / 18$ & 11.1 & $3 / 7$ & 42.9 \\
\hline $55-64$ & $14 / 65$ & 21.5 & $6 / 47$ & 12.8 & $6 / 14$ & 42.9 \\
\hline $65-74$ & $36 / 129$ & 37.9 & $20 / 97$ & 20.6 & $8 / 22$ & 36.4 \\
\hline $75-84$ & $80 / 205$ & 39.0 & $59 / 179$ & 33.0 & $14 / 19$ & 73.7 \\
\hline$\geqslant 85$ & $69 / 128$ & 53.9 & $54 / 106$ & 50.9 & $10 / 15$ & 66.7 \\
\hline Total & $\begin{array}{l}204 / \\
554\end{array}$ & 36.8 & $\begin{array}{l}141 / \\
447\end{array}$ & 31.5 & $41 / 77$ & 53.2 \\
\hline
\end{tabular}

Mortality follow up based on 554 subjects. $\mathrm{D}=$ No of deaths; $\mathrm{S}=$ No of strokes.

type could not be made with the available information (three men and 14 women). In men, cerebral infarction was diagnosed in 250 $(80.9 \%)$ of the patients, intracerebral haemorrhage in $50(16.2 \%)$, and subarachnoid haemorrhage in six $(1.9 \%)$. For women, these figures were $197(80.1 \%), 27(11.0 \%)$, and eight (3.3\%), respectively. For patients with cerebral infarction, the probable stroke subtype was atherosclerosis in 75 patients, lacunar infarction in 71 , cardioembolic stroke in 127, and infarction of unknown cause in 174 .

Survival analysis was based on 554 patients. One patient was lost to follow up before 28 days and 23 patients were lost to follow up by a year. During the first 28 days $147(26.5 \%)$ patients died and $204(36.8 \%)$ by the end of the follow up period. One year mortality increased with age in men and women from $18.5 \%$ (five out of 27 ) for those aged 18-54 years up to $53.9 \%$ (69 out of 128) for those aged 85 years and over (table 2).

The cumulative survival rate from stroke by major subtypes and sex is given in table 3. The overall 1 year probability of survival of the study population after first ever stroke was 0.63 (95\% CI 0.59-0.67). No differences were seen between men and women. Patients with a cerebral infarction (0.68 (95\% CI 0.64-0.72)) had a better probability of survival than patients with intracerebral haemorrhage $(0.46$ (95\% CI $0.35-0.57)$ ). The number of cases with a subarachnoid haemorrhage was too small to provide reliable confidence intervals. As shown by the Kaplan-Meier estimates (fig 2) most of the fatal events occurred early after stroke onset except in patients with a lacunar infarction. Moreover, patients with a lacunar stroke had the best prognosis $(0.94$ (95\% CI $0.86-0.98)$ ) compared with those of any other stroke subtype (log rank test, $\mathrm{p}<0.001)$. Probability of survival in patients with cardioembolic stroke $(0.51,(95 \%$ CI $0.43-0.60)$ ) was similar to that of patients with intracerebral 
Table 3 One year survival probability from stroke by type of stroke and sex

\begin{tabular}{|c|c|c|c|c|c|c|}
\hline & \multicolumn{2}{|l|}{ All events } & \multicolumn{2}{|c|}{ Cerebral infarction } & \multicolumn{2}{|c|}{$\begin{array}{l}\text { Intracerebral } \\
\text { haemorrhage }\end{array}$} \\
\hline & Survival & $95 \% C I$ & Survival & $95 \% C I$ & Survival & $95 \% C I$ \\
\hline Men & 0.65 & $0.60-0.70$ & 0.70 & $0.64-0.76$ & 0.50 & $0.36-0.64$ \\
\hline Women & 0.59 & $0.53-0.65$ & 0.65 & $0.58-0.72$ & 0.40 & $0.21-0.59$ \\
\hline All subjects & 0.63 & $0.59-0.67$ & 0.68 & $0.64-0.72$ & 0.46 & $0.35-0.57$ \\
\hline
\end{tabular}

Kaplan-Meier estimation for 1 year survival probability.

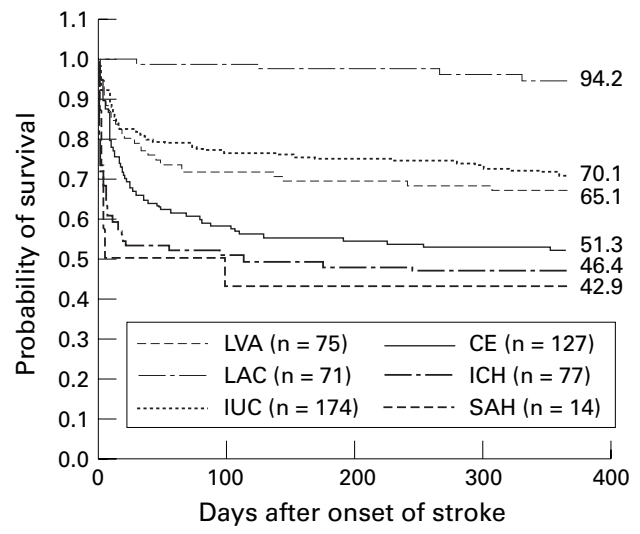

Figure 2 One year survival curves by all stroke subtypes. LVA=large vessel atherothrombotic infarction;

$L A C=$ lacunar infarction; IUC=infarction unknown cause; $C E=$ cardioembolic infarction; $I C H=$ intracerebral haemorrhage; $S A H=$ subarachnoid haemorrhage.

haemorrhage (0.46 (95\% CI 0.35-0.57)). Patients with atherosclerotic stroke and infarction of unknown cause had a probability of survival of $0.65(95 \% \mathrm{CI} 0.55-0.76)$ and 0.70 (95\% CI 0.63-0.77) respectively.

Determinants of 1 year mortality are presented in table 4 . In the univariable analysis some established risk factors were related to death at 1 year, but only age and Glasgow coma scale remained significant independent predictors of the outcome in the multivariable model. Exclusion of the early deaths (within 28 days) did not materially alter the findings in the univariable and multivariable regression analyses.

Table 4 Univariable and multivariable determinants of 1 year mortality

\begin{tabular}{|c|c|c|c|c|}
\hline \multirow[b]{2}{*}{ Risk factor } & \multicolumn{2}{|c|}{ Univariable model } & \multicolumn{2}{|c|}{ Multivariable model } \\
\hline & $H R$ & $95 \% C I$ & $H R$ & $95 \% C I$ \\
\hline Age $(/ y)$ & 1.04 & $1.02-1.05$ & 1.04 & $1.02-1.05$ \\
\hline Women & 1.25 & $0.95-1.65$ & 0.92 & $0.69-1.24$ \\
\hline Smoking & 1.03 & $0.72-1.44$ & & \\
\hline Hypertension & 1.11 & $0.78-1.59$ & & \\
\hline Hypercholesterolaemia & 0.90 & $0.68-1.19$ & & \\
\hline Alcohol consumption & 1.01 & $0.67-1.53$ & & \\
\hline Diabetes mellitus & 1.29 & $0.97-1.73$ & 1.16 & $0.87-1.58$ \\
\hline Transient ischaemic attacks & 1.01 & $0.70-1.46$ & & \\
\hline Atrial fibrillation & 1.52 & $1.15-2.01$ & 1.07 & $0.79-1.46$ \\
\hline Myocardial infarction & 1.22 & $0.78-1.92$ & & \\
\hline Angina pectoris & 1.26 & $0.86-1.83$ & & \\
\hline Congestive heart failure & 1.43 & $1.01-2.01$ & 1.14 & $0.77-1.68$ \\
\hline Valvular heart disease & 1.34 & $0.63-2.84$ & & \\
\hline \multicolumn{5}{|l|}{ Glasgow coma scale } \\
\hline$(2 v 1)$ & 2.63 & $1.83-3.80$ & 2.88 & $1.99-4.17$ \\
\hline$(3 v 1)$ & 8.29 & $5.89-11.67$ & 8.06 & $5.61-11.58$ \\
\hline$(4 \vee v 1)$ & 18.93 & $10.22-35.93$ & 17.56 & $9.35-32.99$ \\
\hline SBP on admission $\dagger$ & 1.01 & $0.97-1.05$ & & \\
\hline DBP on admissiont & 1.02 & $0.94-1.10$ & & \\
\hline
\end{tabular}

$\mathrm{HR}=$ Hazard ratio; $\mathrm{SBP}=$ systolic blood pressure; $\mathrm{DBP}=$ diastolic blood pressure.

${ }^{\star}$ Glasgow coma scale entered as $1=($ score $14-15) ; 2=($ score $8-13) ; 3=($ score $4-7) ; 4=($ score 3$)$. Baseline score $=1$.

†SBP and $\mathrm{DBP} / 10 \mathrm{~mm} \mathrm{Hg}$

Based on data from 328 subjects.
Table 5 One year functional outcome after stroke (\%) by age and $\operatorname{sex}{ }^{\star}$

\begin{tabular}{|c|c|c|c|c|c|c|}
\hline \multirow[b]{2}{*}{ Age (y) } & \multicolumn{2}{|l|}{ Men } & \multicolumn{2}{|l|}{ Women } & \multicolumn{2}{|l|}{ Total } \\
\hline & $C / S$ & $\%$ & $C / S$ & $\%$ & $C / S$ & $\%$ \\
\hline $18-54$ & $4 / 15$ & 26.6 & $2 / 7$ & 28.6 & $6 / 22$ & 27.2 \\
\hline $55-64$ & $5 / 29$ & 17.2 & $4 / 21$ & 19.1 & $9 / 50$ & 18.0 \\
\hline $65-74$ & $12 / 54$ & 22.2 & $13 / 30$ & 43.3 & $25 / 84$ & 29.7 \\
\hline $75-84$ & $20 / 62$ & 32.6 & $22 / 55$ & 40.0 & $42 / 117$ & 35.9 \\
\hline$\geqslant 85$ & $12 / 34$ & 35.3 & $8 / 21$ & 38.1 & $20 / 55$ & 36.3 \\
\hline Total & $53 / 194$ & 27.4 & $49 / 134$ & 34.8 & $102 / 328$ & 31.1 \\
\hline
\end{tabular}

Values are percentage of patients that are unable to look after their own affairs (modified Rankin score 3-4-5).

$\mathrm{C}=$ Cases with modified Rankin score $3-4-5, \mathrm{~S}=$ surviving stroke subjects.

Based on 328 subjects whose functional status could be assessed.

Data on functional outcome 1 year after stroke were available for 328 patients (204 died, 23 patients were lost to follow up, table 5). Of the survivors, nearly $70 \%$ of the patients were functionally independent - that is, were able to look after their own affairs after 1 year. Of the patients who had a cerebral infarction, 43 out of $168(25.6 \%)$ men and 47 out of 120 $(36.7 \%)$ women were dependent after 1 year. The percentages for intracerebral haemorrhage (11 from 33 survivors) and subarachnoid haemorrhage (one from six survivors) were based on too few numbers to allow meaningful analysis.

In the univariate analysis dependence was related $(p<0.10)$ to increasing age, atrial fibrillation, myocardial infarction, and the Glasgow coma scale score. In a multivariable logistic regression model, age, atrial fibrillation and Glasgow coma score (category $3 v 1$ ) remained associated with dependency after stroke (table $6)$.

\section{Discussion}

The importance and strength of our study rests on the fact that it is a prospective population based study of acute first ever strokes with high rates of patients with CT performed to distinguish infarction from haemorrhage and a fairly complete follow up for 1 year. In hospital based studies, the categorisation of strokes into the different subtypes is more accurate, but there might be a bias due to local practice patterns in the selection of patients to be admitted to hospital, in particular "mild" strokes in very old patients may not lead to admission. ${ }^{12}{ }^{14}$ On the other hand, prospective population based studies give us a more precise epidemiological picture about the incidence of strokes but the differentiation between the different stroke subtypes is generally less accurate. Even though a great majority of our patients were in hospital, we encountered considerable difficulties in defining a stroke mechanism and this might reflect a limitation of our study. In our study, $81.8 \%$ of patients had brain CT performed and in the remainder the GHSDS was used. The distribution of stroke subtypes in our study is similar to those reported from other industrialised western countries. ${ }^{15}$

The overall case fatality rate at 28 days ranks among those reported by other studies and was similar in men and women. ${ }^{16-18}$ After 1 year, 
Table 6 Univariable and multivariable determinants of 1 year functional outcome

\begin{tabular}{|c|c|c|c|c|}
\hline \multirow[b]{2}{*}{ Risk factor } & \multicolumn{2}{|c|}{ Univariate model } & \multicolumn{2}{|c|}{ Multivariate model } \\
\hline & $R R$ & $95 \% C I$ & $R R$ & $95 \% C I$ \\
\hline Age $(/ y)$ & 1.02 & $1.00-1.04$ & 1.03 & $1.00-1.05$ \\
\hline Women & 1.50 & $0.93-2.41$ & 1.31 & $0.80-2.16$ \\
\hline Smoking & 1.10 & $0.56-2.17$ & & \\
\hline Hypertension & 1.48 & $0.78-2.82$ & & \\
\hline Hypercholesterolaemia & 1.03 & $0.64-1.67$ & & \\
\hline Alcohol consumption & 0.51 & $0.21-1.23$ & & \\
\hline Diabetes mellitus & 0.68 & $0.39-1.18$ & & \\
\hline Transient ischaemic attacks & 0.71 & $0.36-1.39$ & & \\
\hline Atrial fibrillation & 1.61 & $0.97-2.69$ & 1.88 & $1.11-3.18$ \\
\hline Myocardial infarction & 0.37 & $0.13-1.13$ & 0.41 & $0.13-1.25$ \\
\hline Angina pectoris & 0.83 & $0.40-1.73$ & & \\
\hline Congestive heart failure & 1.22 & $0.61-2.46$ & & \\
\hline Valvular heart disease & 0.89 & $0.17-4.58$ & & \\
\hline \multicolumn{5}{|l|}{ Glasgow coma scale: $†$} \\
\hline$(2 \vee 1)$ & 1.43 & $0.69-2.97$ & 1.74 & $0.81-3.74$ \\
\hline$(3 v 1)$ & 15.23 & $1.80-128.47$ & 17.94 & $1.98-163.41$ \\
\hline SBP on admission $\ddagger$ & 1.04 & $0.97-1.11$ & & \\
\hline DBP on admission $\ddagger$ & 0.98 & $0.85-1.13$ & & \\
\hline
\end{tabular}

$\mathrm{RR}=$ Relative risk; $\mathrm{SBP}=$ systolic blood pressure; $\mathrm{DBP}=$ diastolic blood pressure.

${ }^{\star}$ Functional outcome defined as patients that are unable to look after their own affairs (modified Rankin score 3-4-5) versus those that are able to look after their own affairs (score 0-1-2).

†Glasgow coma scale entered as $1=($ score $14-15) ; 2=($ score $8-13) ; 3=($ score $4-7) ; 4=($ score 3 , all patients died after one year). Baseline score $=1$.

$\ddagger \mathrm{SBP}$ and $\mathrm{DBP} / 10 \mathrm{mmHg}$.

Based on data from 328 subjects.

$37 \%$ of patients with stroke had died stressing the fact that the mortality after a stroke is high. No differences were found between men and women, whereas patients with intracerebral haemorrhage had almost a twofold probability of dying than patients with infarcts.

Few prospective population based studies give results for 1 year mortality by age, sex, and pathological type with adequate numbers of events and $95 \%$ CI estimates. In a study from the L'Aquila region of central Italy, mortality at 1 year was consistent with our estimates (36.9\%, 95\% CI 33.6-40.2) with similar results for cerebral infarction and intracerebral haemorrhage $\quad(32.4 \%$ and $58.2 \%$ respectively). ${ }^{16}$ Survival data from Rochester, MN, USA for the years 1985-89 showed no significant differences compared with our findings for women ( $64 \%$ for cerebral infarction and $34 \%$ for haemorrhage), whereas for men the probability of survival in patients with cerebral infarction was higher than in the present study $(79 \%){ }^{19}$ The Oxfordshire Community Stroke Project (OCSP) provided important and accurate information on stroke incidence and survival. ${ }^{20}$ In 1 year the overall mortality for stroke was $31 \%$ (95\% CI 27-35), significantly below ours, and this was mainly attributed to the death of patients with cerebral infarction $(23 \%, 95 \%$ CI 19-27). The different age structure of the study population may explain in part the differences in mortality risk for cases with cerebral infarction between the last two studies and our study. A striking relation exists between age and stroke mortality as shown in table 2, and our stroke population was older compared with those of Rochester and Oxfordshire. The high rates of comorbidity (hypertension, diabetes, atrial fibrillation) may contribute to our relatively poor prognosis compared with other community based studies. Additionally, in our study a less optimum case ascertainment of mild cases of out of hospital stroke may have occurred, thus resulting in a higher 28 day case fatality rate. ${ }^{9}$ Similarly, mild cases may be missed due to cross boundary medical care.

Our study shows that patients with lacunar stroke have a high survival rate at 1 year, results comparable with a study from Minnesota $(97 \%)$ and to the OCSP $(90.2 \%){ }^{20}{ }^{21} \mathrm{By}$ contrast, patients with a probable cardioembolic infarction have a worse prognosis, results that might be related to the high prevalence of atrial fibrillation in our population (34\%).

At 1 year, independence for activities of daily living was $68.9 \%$ with no differences between men and women. Again, a striking relation to age was seen. Few prospective population based studies have considered functional outcome 1 year after acute stroke. In the Oxfordshire study $65 \%$ of the survivors of stroke were functionally independent at 1 year, without differences among stroke subtypes. ${ }^{22}$ In another study from southeast England, results were similar $(66 \%$ independent $) .{ }^{23}$ The fact that a high proportion of our patients were independent for activities of daily living might have been biased by the relatively large death rate. If these patients had survived, they would very likely have had a low functional status.

Our findings are in agreement with previous studies, which found that age and consciousness level are the major contributing factors for early as well as for 1 year mortality. ${ }^{24-27}$ Low consciousness level on admission probably reflects the severity of brain damage which is not only the major factor contributing to the early mortality, but also predisposes to the functional dependence of the survivors. Increasing age is the second factor that independently affects 1 year mortality and disability. Older victims of stroke are susceptible more often to complications such as infections or cardiac events. ${ }^{24}$

Our study shows that atrial fibrillation is an independent prognostic factor of functional ability after 1 year from stroke onset. Moreover, this common arrhythmia seemed to have a high prevalence among our stroke victims. Atrial fibrillation, a major factor contributing to stroke, causes massive brain infarcts, resulting in severe neurological deficits with persistent functional dependence and higher mortality ${ }^{28-30}$ Recent reports show trends of an increasing prevalence of atrial fibrillation and a reluctance of physicians to prescribe anticoagulants for primary stroke prevention. ${ }^{3132}$

The study of the relation between demographic factors and disability may further help the health authorities to distribute effectively the available funds required for the care of stroke victims and to establish a long term plan involving medical and rehabilitation services for these patients. Moreover, strategies for a more efficient primary prevention of stroke in patients with atrial fibrillation are necessary, and future trials with new drugs or combination antiplatelet-anticoagulant drugs are needed for the older population.

\footnotetext{
1 Bonita R. Epidemiology of stroke. Lancet 1992;i:342-4.

2 Thom JT. Stroke mortality trends: an international perspective. Ann Epidemiol 1993;3:509-18.

3 WHO MONICA project. Stroke trends in the WHO MONICA project. Stroke 1997;28:500-6.
} 
4 Antiplatelet Triallists Collaboration. Collaborative overview of randomised trials of antiplatelet therapy. I. Prevention of death, myocardial infarction, antiplatelet therapy in various categories of patients. $B M Y$ 1994;308:81-106.

5 Malmgren R, Bamford J, Warlow C, et al. Geographical and secular trends in stroke incidence. Lancet 1987;ii:11961200.

6 Bonita R, Stewart A, Beaglehole R. International trends in stroke mortality: 1970-85. Stroke 1990;20:989-92.

7 Feinleib M, Ingster L, Rosenberg H, et al. Time trends, cohort effects, and geographic patterns in stroke mortality in the United States. Ann Epidemiol 1993;3:458-65.

8 World health statistics annually. Geneva: World Health Organisation, 1990, 1991, 1992

9 Vemmos KN, Bots ML, Tsibouris PK, et al. Incidence and case fatality of stroke in the south of Greece: the Arcadia Stroke Registry. Stroke 1999;30:363-70.

10 Aho K, Harmsen P, Hatano S, et al. Cerebrovascular diseases in the community: results of a WHO collaborative diseases in the community: results of a WHO co

11 Allen CMC. Clinical diagnosis of the acute stroke syndrome. $Q$ f Med 1983;52:515-23.

12 Bamford J, Sandercock P, Dennis J, et al. A prospective study of acute cerebrovascular disease in the community: the Oxfordshire community stroke project 1981-6. 2: incidence, case fatality rates and overall outcome at one year of cerebral infarction, primary intracerebral and subarachnoid haemorrhage. f Neurol Neurosurg Psychiatry 1990;53 $16-22$.

13 van Swieten JC, Koudstaal PJ, Visser MC, et al. Interobserver agreement for the assesment of handicap in stroke patients. Stroke 1988;19:604-7.

14 Sudlow CLM, Warlow CP. Comparing stroke incidence world wide: what makes studies comparable. Stroke 1996;27:550-8.

15 Sudlow CLM, Warlow CP, for the International Stroke Incidence Collaboration. Comparable studies of the incidence of stroke and its pathological types. Results from incidence of stroke and its pathological types. Results

16 Carolei A, Marini C, Di Napoli M, et al. High stroke incidence in the prospective community-based L'Aquila Registry (1994-8): first year results. Stroke 1997;28:25006.

17 Bonita R, Anderson C, Broad JP, et al. Stroke incidence and case fatality in Australasia: a comparison of the Auckland and Perth population-based stroke registers. Stroke 1994 25:552-7.
18 Feigin VL, Wiebers DO, Nikitin YP, et al. Stroke epidemiology in Novosibirsk, Russia: a population-based study. Mayo ogy in Novosibirsk, Russia:

19 Brown RD, Whisnant JP, Sicks JD, et al. Stroke incidence, prevalence and survival: secular trends in Rochester, Minnesota, through 1989. Stroke 1996;27:373-80.

20 Sacco SE, Whisnant JP, Broderick JP, et al. Epidemiological characteristics of lacunar infarcts in a population. Stroke 1991;22:1236-41.

21 Bamfort J, Sandercock P, Jones L, et al. The natural history of lacunar infarction: The Oxfordshire Community Stroke Project. Stroke 1987;18:545-51.

22 Dennis MS, Burn JSP, Sandercock PAG, et al. Long-term syrvival after first-ever stroke: the Oxfordshire Community Stroke Project. Stroke 1993;24:796-800.

23 Taub NA, Wolfe CDA, Richardson E, et al. Predicting disability of first-time stroke sufferers at 1 year: 12 -month follow-up of a population-based cohort in southeast England. Stroke 1994;25:352-7

24 Howard G, Walker MD, Becker C, et al. Community hospital-based stroke programs: North Carolina, Oregon and New York, III: factors influencing survival after stroke: proportional hazards analysis of 4219 patients. Stroke 1986;17:294-9.

25 Chambers BR, Norris JW, Shurvell BL, et al. Prognosis of acute stroke. Neurology 1987;37:221-5.

26 D'Alessandro G, Di Giovanni M, Roveyaz L, et al. Incidence and prognosis of stroke in Valle d'Aosta, Italy. Stroke 1992; 23:1712-15.

27 Korv J, Roose M, Kaasik AE. Stroke registry of Tartu, Estonia, from 1991 through 1993. Cerebrovasc Dis 1997;7:15462

28 Yamanouchi $\mathrm{H}$, Tomonaga $\mathrm{M}$, Shinada $\mathrm{H}$, et al. Nonvalvular atrial fibrillation as a cause of fatal massive cerebral infarction in the elderly. Stroke 1989;20:1653-6.

29 Candelise L, Pinardi G, Morabito A, et al. Mortality in acute stroke with atrial fibrillation. Stroke 1991;22:169-74.

30 Sandercock P, Bamford J, Dennis M, et al. Atrial fibrillation and stroke: prevalence in different types of stroke and and stroke: prevalence in different types of stroke and influence on early and long term prognosis. (Oxford

31 Brass ML, Krumholz HM, Scinto JM, et al. Warfarin use among patients with atrial fibrillation. Stroke 1997;28: 2382-9.

32 Wolf PA, Benjamin EJ, Belanger AJ, et al. Secular trends in the prevalence of atrial fibrillation: The Framingham Study. Am Heart f 1996;131:790-5. 